\title{
Open and Distance Learning Transformed: Possible Adaptations to Suit Special Contexts
}

\author{
G.I.C. Gunawardena ${ }^{1}$ and G.D Lekamge $^{2}$ \\ gunawardena@hotmail.com,gdlek@ou.ac.lk
}

\begin{abstract}
With the integration and advancement of new technology, Distance and Open Learning has taken different forms. It has gradually become more general, less non-traditional and sometimes a main trend in several countries. This article discusses the concept of Open and Distance Learning and focuses on the strengths and weaknesses of different models of ODL, especially for countries like Sri Lanka. The Correspondence Model based on print technology mostly has now evolved into the Intelligent Flexible Learning Model which aims to capitalize on the fastness of the Internet and the Web. While the Fifth Generation of ODL offers a large number of advantages, several constraints such as marginalization of certain groups of learners who were not raised with digital technologies, the credibility of data and information downloaded from the Internet, speed of the Internet, the time taken to download and upload materials and the time taken by the instructors to respond to students have been identified. While technology is an effective strategy to overcome barriers to education, its use could also impose other barriers. The authors stress that any technology which does not facilitate those who are really disadvantaged and bequeaths advantages only to those who already have access to formal education should be weighed carefully for its costs and benefits.
\end{abstract}

\section{Introduction}

Open and Distance Learning (ODL) has emerged as a panacea for all ills faced by educational systems in both developed and developing countries. It has taken many different forms with the integration and advancement of new technology. As time went on, changes occurred in the concept of distance education and it has gradually become more general, less non-traditional and sometimes a main trend in several countries. This article is devoted to a discussion of the concept of Open and Distance Learning and how the concept as well as the methodologies evolved over time to become a more sophisticated and an attractive form of learning for students. It will also focus on the strengths and weaknesses of different models of ODL, especially for countries like Sri Lanka and discuss the multi-generational model suggested by Willems (2005) to maximize advantages and minimize disadvantages of technology-based ODL. 


\section{Concept of Open and Distance Learning}

Distance Education is defined by Rumble (1989) as "a process in which there must be a teacher, one or more students: a course or a curriculum that the teacher is capable of teaching and the student is trying to learn; and a contract, implicit or explicit, between the student and the teacher or the institution employing the teacher, which acknowledges their respective teaching-learning roles ". The first form of distance education, 'Correspondence Education' consisted of 'batches of study material sent by post to the student who then completed the required reading and exercises and returned the latter to the college for assessment by an appointed personal tutor' (Legge, 1982). This mode was made accessible only to those who were literate and possessed some qualifications and as a result it could never supplement the formal education system of the time.

Later it emerged as an educational mode - supplementary, complementary and an alternative to conventional/traditional education. Keegan (1986) thus considered Distance Education as a teaching process "achieved by bridging the physical distance between student and teacher by means of at least one appropriate technical medium" while Moore (1973) defined it as a "family of instructional methods in which the teaching behaviors are performed apart from learning behaviors... so that communication between the teacher and the learner must be facilitated by print, electronic mechanical or other devices". Bates (1995) defined distance education as a one way process "by which learners can study in a flexible manner, by studying at a distance from the originator of the teaching material; students can study at their own time, at the place of their choice and without face to face contact with the teacher". Moore and Kearsley (1996) describe distance education as "planned learning that normally occurs in a different place from teaching and as a result requires special techniques of course design, special instructional techniques, special methods of communication by electronic and other technology, as well as special organizational and administrative arrangements".

As Distance Education gradually came to be referred as Open Learning, new definitions emerged. Thus Bates (1995) conceptualizes Open Learning primarily as a goal, or as an educational policy, "the provision of learning in a flexible manner, built around the geographical, social time constraints of individual learners rather than those of an educational institution". However, in British usage, the distinction between Distance Education and Open Learning is blurred 
Open and Distance Learning Transformed: Possible Adaptations to Suit Special Contexts

(Thorpe, 1988 p 56).

Maxwell (1995) defines Open Learning as "a student centered approach to education that removes all barriers to access while providing a high degree of learner autonomy". It is argued that in Open Learning, there is openness in access, content, delivery system and assessment. Wylie (1996) referred to the following aspects of Open Learning:

1. It serves learners who look for flexible entry provision of learning materials.

2. It is responsive to learner needs.

3. It enables the learner to negotiate content on a more individualized basis.

4. It is basically resource-based and offers alternative strategies.

5. It is possible to be used in quite different places, such as in homes, in workplaces and in study centres.

During the recent past, Distance Education and Open Learning became amalgamated to form the concept of Open and Distance Learning (ODL). Bates (1995) points out that "Open and Distance Learning gives a second chance to people who for academic, personal or social reasons are unable to enter or complete higher education on leaving the school system". It involves the use of new methodstechnical and / or non technical- to improve the flexibility and feasibility of learning in terms of space, time, choice of content and teaching-learning and or to improve access to educational systems from a distance" (Socrates \& Youth Technical Assistance Office, 1995). The automated course ware production systems, automated pedagogical advice systems and automated business systems of Open and Distance Learning today has become one of the most effective and least costly education endeavor in the fast changing world.

In the next section of the article we will basically focus upon the evolution of Open and Distance Learning over the last two decades. This discussion will also overlap with the early models of Distance Education and Open Learning which we discussed above, in order to provide a snapshot of developments over time. 


\section{Evolution of Open and Distance Learning over Two Decades}

The signal characteristic of Open and Distance Learning (ODL) during the past two decades is indisputably the adoption of new technologies to increase access to education and improve its quality. As Berge and Collins (1995) noted, the paradigmatic shifts in education have corresponded to advances in technology throughout the history of human communication. In the European Community, for example, several policy orientations could be recognised to have influenced public initiatives to support ODL and learning technologies (Dondi, 1997):

- first of all, the concern to innovate education and training systems by increasing accessibility and flexibility of learning opportunities, to rationalise expenditure and to introduce an investment perspective in the education/training expenditure;

- the concern to add a European dimension to national education and training provision;

- the concern to guarantee quality of supply and to "protect consumers" against bad practice and unreasonable expectations;

- the concern to develop a market area for information and communication technologies;

- the concern to develop a European multimedia industry able to compete in a global market.

Feinsten et al (2008) note, technology is a central driver of life-long learning - particularly as information and knowledge are central to individual and economic wellbeing in the knowledge economy.

Initially, Nipper (1989) proposed three 'generations' in distance learning: (1) traditional correspondence style of learning which combined print media with postal delivery, (2) introduction of learning materials such as audio and video cassettes and broadcast mediain addition to the co-existing print media products and; (3) using computer technology and the Internet to deliver learning products.

Taylor (1999), on the other hand, proposed five generations of distance education: 
Open and Distance Learning Transformed: Possible Adaptations to Suit Special Contexts

1. The Correspondence Model based on print technology mostly the First Generation;

2. The Multi-Media Model based on print, audio and video technologies and some computer based courseware - the Second Generation;

3. The Tele-learning Model based on applications of telecommunication technologies to provide opportunities for synchronous communication - the Third Generation;

4. The Flexible Learning Model based on online delivery via the Internet - The Fourth Generation; and

5. The Intelligent Flexible Learning Model which aims to capitalize on the fastness of the Internet and the Web - the Fifth Generation (Dept. of Education, Training and Youth Affairs, Australia, 2001).

Each of these 'Generations', can be linked to the specific production and distribution of distance learning materials utilized at a particular time in addition to the communication technologies (media) used to deliver them to enrolled students, who are separated by time, place and/or pace of learning.

It is opportune at this point to delve deeper into the evolution of Open and Distance Learning and the advantages and disadvantages of each generation of ODL. The Correspondence Model provided increased access to vast numbers of potential learners of mature age who were resident in remote areas, and who being employed were unable to attend face-to-face sessions. It also supported others who lacking the requisite formal qualifications could not proceed to tertiary education. The unreliable quality of print materials could be attributed to the following: the 'customers' of distance education were heterogeneous in nature, especially in respect of formal educational qualifications and that those who produced the print materials differed from institution to institution. Although some strategies for improving active participation such as Pre-Tests, Self-Assessment Questions, Activities, illustrations and Check your Understanding were incorporated, the print materials provided had basically to be read and understood. The first generation of ODL thus focused mainly on transmission of knowledge.

Communication with peers and course tutors was limited to occasional Day Schools and feedback for written assignments the turn-around time for which could vary. Julie Willems (2005) identifies the problems 
that she faced as an ODL student, such as typing the assignments on a typewriter, the use of airmail paper to reduce bulk and weight in order to keep the postage costs down, and keeping back-up copies of correspondence and assignments on carbon paper. Delays in delivery of print materials, even when strict deadlines for submission of assignments are stipulated, were not infrequent. However, print materials were cheap and portable and could be read whenever time was available.

The Second Generation was an advance on the first. Yet even though multi-media had been included in the second generation technologies, these were either never used or sparingly used in developing countries. This was mainly due to the problems associated with access to these technologies and the infrastructure facilities and equipment needed for their use at both the institutional level and on the part of the students. The major advantage of the Multi-Media Model is the use of multimedia rather than restriction to the single mode of print. As Willems points out, it 'humanized' the whole process. There was the possibility now of listening to an expert lecturer who had developed the print matter rather than to a novice or an inexperienced tutor at a Day School. Audios were simpler to use, within reach of the students who could afford to buy a cassette player and also enabled the student to engage in other personal activities while listening to 'courses'. Flexibility with regard to time, place and pace of study could be ensured. While the quality of ODL visibly improved with the introduction of audios and videos, the possibility should not be ignored that newer technologies could be beyond the reach of some of the distance learners, especially those in developing countries. In those countries ODL institutions experience a dearth of staff with professional and technical skills to develop multi-media materials, a lack funding and equipment and the possibility that poorer students would not possess the necessary technology to access the multi-media mode (Else and Hicks, 1998; Willems, 2005).

The Tele-learning Model is based on the use of synchronous interactive technologies to facilitate remote learning. This Model is extremely useful for multi-campus, multi-centre educational institutions, as it not only saves the travel expenses and time of experienced instructors but also ensures equity in delivery for all learners, whichever campus or centre they participate in for face-to-face sessions. Although broadcasting and use of television can be both affordable and attractive to learners, and are being widely used in countries like India, Korea and Thailand the economies of scale are small, the flexibility for learners is little and the average cost per student tends to be high 
(Bates, 2008; Willems, 2005). When learners perceive programmes as costly, even when attractive, demand is likely to decrease and institutions, especially in developing countries, would find it difficult to use such technologies. 'On and off college campuses, e-learning could not take off until wide-bandwidth internet access was readily available, until smart classrooms were constructed, and until all faculty and students had access to computers' (Zemsky and Massy, 2004: 8). It has been pointed out that "Key barriers remain at the university level, including infrastructure, funding and staffing issues, and resistance by faculty, e.g., because of added workload, intellectual property issues (OECD, 2005).

The Fourth Generation of distance learning, the Flexible Learning Model enables the enhancing of interactivity through multi-media, computer-mediated communication offered by connection to the internet and web-based instructions. These technologies also enable the use of highly-refined materials. The Model facilitates studentteacher and student-student interaction at a distance and also for students to collaborate in learning anywhere at any time. Such components as electronic mail (e-mail), computer conferencing and bulletin boards are used in this model. The major benefit of this Model is the opportunity given to distance learners to experience being part of a learning community. Student satisfaction surveys suggest that elearning has positively affected the quality of teaching and learning. ICTs have altered the overall learning experience of students by relaxing time and space constraints and by providing easier access to information and materials-an achievement that should not be downplayed (OECD, 2005). More than ever before, delivery of learning materials is faster and cheaper as e-mail supersedes earlier modes of communication. ODL thus becomes transformed from an academic to a social process. The social learning process enables students to move from the competitive tertiary education mode to a more collaborative mode, from which all can profit.

Moreover, by this time, most nations had invested in the computer industry and thus had developed the required infrastructure and equipment to utilise technology. Yet it was possible that a specific group of distance learners could still remain un-served if the campus and the centre of their university were not located close to their residences, if they did not have access to computer and internet technology in their places of work or home. As Shank (2008) suggests, among learners in the digital age, there are substantial and identifiable differences between learners who were raised with digital technologies ("Netgens") and those who were not. Inequities that surface with the $2^{\text {nd }}$ 
and $3^{\text {rd }}$ generations of ODL could have got aggravated in the $4^{\text {th }}$ generation. Among other constraints are the credibility of data and information downloaded from the Internet, speed of the Internet and the time taken to download and upload materials and the time taken by the instructors to respond to transmitted messages by students and actual participation in the opportunities made available for collaboration. For example, Hall and Cotterill (2004) highlighted the difficulty in getting students to participate in electronic discussion forums. Reasons suggested were (1) that students do not want their thoughts to be publicly exposed and subjected to criticism, (2) any contribution made is permanent and cannot be justified or explained immediately as in face to face sessions, (3) student contributions may be misinterpreted without the opportunity to justify reasoning, (4) students do not want to look stupid if their answer is wrong and (5) students are reluctant to criticize their peers.

The University of Southern Queensland (USQ) promises an e-learning environment that supports a learning process that is interactive, nonlinear and collaborative. The features of this Model as implemented at USQ include the use of an interactive study chart as a basic navigational tool, which sets the broad parameters of the subjectmatter content to be investigated, and lists a number of exemplary references. Students are free to surf the Net for supplementary teaching-learning resources that meet their specific needs. This model (Dept. of Education, Training and Youth Affairs, 2001) enables students to upload and download assignments, interact with other students, teaching staff and other experts who act as mentors, through the use of Computer Mediated Communication (CMC) primarily through the deployment of asynchronous discussion groups for specific content issues as well as for informal social interaction. The benefit of the system is shown as the opportunity for communication on a 'one to many' basis, so that all students may benefit and not only the student who asked the question. Students' comments enrich the depth and quality of the dialogue and these contributions are especially valuable where students give examples of application in different cultural contexts. Intelligent object databases that have been developed by USQ enables the search engine on the receipt of an electronic query from a student, to seek an appropriate match with a previously asked question, which if successful, triggers a personalized response to the current question without concurrent human intervention. The planners believe that as the intelligent object databases become more comprehensive, the institutional variable costs for the provision of effective student support will tend towards zero. A central feature of the Fifth Generation Model is the development of a customizable e- 
Interface, a campus portal through which students, staff and other stakeholders can engage with the university in a highly interactive manner. The USQ e-university project has also launched an oncampus wireless networking initiative, to enable access to the Internet from about $90 \%$ of on-campus locations. It is claimed that, Fifth Generation distance education is less expensive and also provides students with better quality tuition and more effective pedagogical and administrative support services.

Some researchers suggest mobile learning as the next generation of elearning/ODL. O'Malley et al (2003) note mobile learning occurs "when the learner is not at a fixed, pre-determined location, or when the learner takes advantage of learning opportunities offered by mobile technologies. Mobile devices include cell phones, Smartphones, Blackberrys, laptop computers and personal media players. When mobile devices are connected with wireless connectivity, learning opportunities increase and can be monitored or coordinated between locations.

The third to fifth generation models described above fall under the broad general area of e-learning. Some studies have suggested that elearning may create an imbalance between the development of computer skills and the fostering of essential academic and thinking skills. In addition, e-learning could foster technology dependencies and isolation, rather than encourage the development of learners who can embrace a range of learning approaches and interact with other learners.

Ungerleider and Burns (2002) have noted the lack of methodologically rigorous evidence of e-learning's effectiveness in promoting achievement, motivation and meta-cognitive learning and in facilitating instruction in content areas in elementary and secondary schools. To be effective, e-learning must be linked to teaching practices that have demonstrated benefits and should be used to reflect the nature of the content and learners' needs and abilities.

Similarly results of the Adultlearning@Home Project (Canadian Council on Learning, 2009) underline several key issues on e-learning. Among these were,

1. E-learning was most associated with the use of technology itself, rather than as a means to learning something else,

2. ICTs appear to reinforce existing patterns of learning and were 
mainly of benefit to people who were already learners or who would have become learners without the availability of ICTs,

Technological problems such as failed equipment or poorly functioning software could also erode the joy and motivation to learn (Dory, 2005).

Willems (2005) provides an insider's view of each of these generations, having participated in each of them. Thus she found that the fourth generation learning experience combined text-based coursework, CDROM and the opportunity to participate in online subject forums and assessable 'small group' made possible by university portal access to assist computer-mediated learning. In the fifth generation, she experienced greater dividends such as the opportunity to communicate with educators and peers, undertake comprehensive literature searches from home, transmit assessments, opportunities to 'meet' other online learners, to learn in a collaborative environment and encourage others in their journey through learning. Above all, she found that it aided consolidation of deep learning. Among the difficulties faced were that download speeds were low, that there were problems of staying connected and that of not having enough memory to download.

\section{Implications for Implementation of Advanced Generations of ODL}

The best model of education, it has to be admitted, is coloured by contextual factors that impinge on its implementation. Table 1 below shows the differences in access to technology in selected countries. 
Open and Distance Learning Transformed: Possible Adaptations to Suit Special Contexts

Table 1: Access to Technology: Selected Countries - 1990 and 2005 (per 1000 people)

\begin{tabular}{|c|c|c|c|c|c|c|c|}
\hline \multirow[t]{2}{*}{$\begin{array}{l}\text { HDI } \\
\text { Rank }\end{array}$} & \multirow[t]{2}{*}{ Country } & \multicolumn{2}{|c|}{$\begin{array}{l}\text { Telephone } \\
\text { Mainlines }\end{array}$} & \multicolumn{2}{|c|}{$\begin{array}{l}\text { Cellular } \\
\text { Subscribers }\end{array}$} & \multicolumn{2}{|c|}{ Internet Users } \\
\hline & & 1990 & 2005 & 1990 & 2005 & 1990 & 2005 \\
\hline 1 & Iceland & 512 & 653 & 38 & 1,024 & 0 & 869 \\
\hline 8 & Japan & 441 & 460 & 7 & 742 & NA & 668 \\
\hline 12 & USA & 545 & 606 & 21 & 680 & 8 & 630 \\
\hline 16 & UK & 441 & 528 & 19 & 1,088 & 1 & 473 \\
\hline 25 & Singapore & 346 & 425 & 17 & 1,010 & 0 & 571 \\
\hline 81 & China & 6 & 269 & NA & 302 & 0 & 85 \\
\hline 99 & Sri Lanka* & 7 & 63 & NA & 171 & 0 & 14 \\
\hline 100 & Maldives & 29 & 98 & 0 & 466 & 0 & 59 \\
\hline 128 & India & 6 & 45 & 0 & 82 & 0 & 55 \\
\hline 136 & Pakistan & 8 & 34 & NA & 82 & 0 & 67 \\
\hline
\end{tabular}




\begin{tabular}{|c|l|c|c|c|c|c|c|}
\hline 140 & Bangladesh & 2 & 8 & 0 & 63 & 2 & 3 \\
\hline 177 & Sierra Leone & 3 & -- & 0 & 22 & 0 & 2 \\
\hline
\end{tabular}

* It is reported that Sri Lanka is the first country in South Asia to adopt mobile phone technology, and that there are 13,500,000 mobile phone users in Sri Lanka in 2010 while $21 \%$ of houses in Western Province have home computer facilities. (The Catalyst, ICTA Bimonthly Newsletter, Issue 07, April, 2010)

Source: UNDP, Human Development Report 2007/2008, Fighting Climate Change: Human Solidarity in a Divided World, New York

The above table clearly illustrates how access to technology is to a large extent a product of development. Among the countries included here, Iceland, UK and Singapore have more cellular subscription than its population. All the countries with more than 400 Internet users per 1000 are in the High Human Development category. The situation is bound to have drastically changed during the last five years in all countries. Growth in Internet users in the world increased by $359 \%$ from 2000 to 2009 and $20.8 \%$ of the world's users were from China (Internet World Stats, 2009). In OECD countries, it has been reported that in Korea, Iceland and Netherlands, more than $80 \%$ of the households have home access to the Internet while 14 others (Sweden, Denmark, Norway, Luxembourg, Germany, Switzerland, Finland, Canada, UK, New Zealand, Australia, Japan, USA and Belgium) have between 60-80 \% households with home access. (OECD, 2008) The percentage of population using the Internet in Sri Lanka in 2008 was reported as 3.7 (Internet World Stats, 2009). Although access to education and distance education, is most imperative in the countries with Medium and Low Human Development, they are the least equipped to make use of the sophisticated Generations of Distance Education.

Moreover, data from surveys in 2005 (World Bank) show that youth aged 15 and older account for 43\% of all Internet users in China, 50\% in Armenia, 53\% in Bolivia, 60\% in Egypt, and 70\% in Indonesia. Across countries surveyed in 2005 the share of 15-24 year-olds who have ever used the Internet varies from less than $01 \%$ in Ethiopia, to $12 \%$ in Indonesia, $13 \%$ in Ghana, 15\% in Egypt and 53\% in China. The 
digital divide also occurs within countries. Computer and mobile phone ownership and the Internet and SMS usage was highest among youth in urban areas and in the more educated and higher household incomes. In Indonesia $59 \%$ of university students had used the Internet compared with $5 \%$ or less among youth with only primary education.

It is also shown that the information gains from the Internet searches are notably less for youth who are unable to read, process and choose among different sources of information or even spell words they are looking for. The difficulties are compounded for many developing country youth by the lack of access to content in the native languages. In $2002,72 \%$ of the world's Internet pages were in English, $7 \%$ in German, 6\% in Japanese, 3\% in Spanish and French, 2\% in Italian, Dutch and Chinese and $01 \%$ or less in any other global languages (World Bank, 2006).

Studies have however suggested that consumer demand for ICTs will continue to increase. Increasingly, governments, educators and businesses have made use of ICTs a priority for providing individuals with the technological skills needed to succeed in today's workplace.

As Wagner, Hassanein and Head (2008) note, when all stakeholders "fulfill their responsibilities to create effective and meaningful elearning experiences, positive outcomes extend beyond success in specific courses and programs to facilitate lifelong learning and discovery.". Each stakeholder group has an important role to play in enhancing the overall learning experience.

- Students and instructors should participate as proactively as possible, provide feedback to improve future experiences, and communicate the learning possibilities that e-learning creates.

- Institutions should provide the technical infrastructure and support needed to enable comprehensive solutions.

- Content and technology providers should provide high-quality, practical solutions that consider learning principles.

- Accreditation bodies should provide and enforce clear guidelines for this new form of learning delivery. 
- Employers need to recognize the validity of this form of education, and work with other stakeholders to ensure that graduates' skills meet the needs of the job market.

Recent studies (Canadian Council on Learning, 2009)) have suggested that today's e-learning efforts are likely to use a combination of methods known as "blended learning" (the use of traditional learning with e-learning). Among the issues that need to be considered are

1. Learners need specific skills - such as computer literacy, information literacy and general literacy - to use ICTs effectively,

2. Those with disabilities need e-learning programmes that address their particular needs,

3. Meeting the needs of 21 st-century learners requires acknowledgement of learner diversity (cognitive, cultural, social, economic) and the need for flexible and accessible content.

4. Quality assurance is critical-to ensure an optimal match between sound teaching theory, learners' needs and the design of technology.

5. Professional development is necessary to ensure that teaching professionals have adequate understanding and technical support.

6. Resource-sharing can facilitate the learning experience, but can also raise concerns about issues of intellectual property protection and copyright.

Even though misgivings about the benefits of using ICT for ODL and for e-learning continue, it is heartening to note the action that are being taken by institutions and countries to fulfill the dreams expressed in incorporating ICT into distance learning/e-learning. Among these are

1. The GOOD Project of USQ (Dept. of Education, Training and Youth Affairs (2001), 
2. Open Educational Resources (OER) that are free, online learning and teaching resources that reside in the public domain,

3. BCcampus and Campus Alberta in Canada, that permit postsecondary institutions to share research and content

4. Library and Archives Canada (LAC), a national strategy to guide Canada's "scientific, cultural, and education communities, businesses, and civil society in the production, use, sharing and preservation of its vast and growing body of digital information."

5. ABRACADABRA, (A Balanced Reading Approach for Canadians Designed to Achieve Results for All) Athabasca University, Northern Ontario School of Medicine, the Sunchild E-Learning Community Model, and the Operating Engineers Training Institute of Ontario is web-based literacy software for early elementary classrooms across Canada

6. The Sunchild E-Learning Community a First Nations-controlled school that provides Aboriginal learners of all ages with access to high-school diploma courses, basic adult upgrading, trades, industry training and university courses

7. The Campusdirect program-the Canada School of Public Service online campus, which allows public service employees throughout Canada and around the world to access more than 350 e-learning resources.

It is also pertinent to note here, the role that governments both national and provincial have to play in making ODL using ICTs effective. Especially as institutions in developing countries are unable to afford the rising costs of incorporating ICT into distance learning, the major part of costs need to be borne by the government. Thus the Canadian federal, provincial and territorial governments have recognized the potential of new learning tools to enrich traditional teaching and extend lifelong learning opportunities and have taken significant steps toward responding to these emerging learning needs and pressures, by making substantial investments in technology, technological infrastructure and education policy. Governments and institutions have initiated many online and technology-enhanced programmes to meet the growing demand for lifelong learning opportunities, and to respond to the expectations of a new internetand technology-savvy generation (Advisory Committee for Online Learning, 2001). 
Charpentier (2006) observed that e-learning strategies and action plans in most countries, other than the U.S., are government-initiated. Furthermore, these wide-ranging government action plans translate into initiatives significant public funding.

Australia, Korea, the U.S., the U.K. and France are examples of countries that have embraced an e-learning agenda, as have multicountry organizations such as the European Union (EU) and the Commonwealth of Learning (COL) (Charpentier, 2006).

\section{Open and Distance Learning in Sri Lanka}

In Sri Lanka, the pioneer organization using limited distance education, was the External Services Agency of the then University of Sri Lanka, established in 1972. Its function was to register candidates for examinations and conduct them. No instruction was provided to students, except for those registered for the Postgraduate Diploma in Education. Regular distance education was introduced only in 1976 with the establishment of the Sri Lanka Institute of Distance Education (SLIDE). The objective of the SLIDE was to provide tertiary level education in the fields of mathematics, science, management and technical studies to those who were unable to continue higher education. At the beginning, the SLIDE offered four main programmes of study: the Higher National Diplomas in Management Studies and in Technology (electrical and electronics and telecommunication technology), and the National Diplomas in Science and in Mathematics. The methodology comprised print, practical and laboratory work and face-to-face sessions and thus was an example of the Correspondence Model.

In 1980, the SLIDE was absorbed into the newly-created Open University of Sri Lanka (OUSL). The OUSL received support from UNESCO to purchase workshop equipment, audio-visual equipment, and printing machinery, to hire foreign and local consultants and to provide research fellowships, which were continued over the years by other donor agencies such as the Japan International Corporation Agency (JICA), the Department of International Development (DFID) UK, and the Asian Development Bank (ADB). The first programmes of study offered by the OUSL were Certificates in Pre-School Education, in Entrepreneurship, and Professional English and the L.LB degree programme and the Postgraduate Diploma in Education. The main medium of instruction was print with a few radio programmes being aired by the Sri Lanka Broadcasting Corporation after 1980. Subsequently the Ministry of Education in 1979 also commenced 
teacher training programmes in the distance mode to train teachers who lacked professional qualifications. This programme was developed with support from the Swedish International Development Agency (SIDA) and the University of Lund. Both institutions mainly used print materials while the OUSL used supplemented these with audios. The introduction of newer technologies occurred in the OUSL with the establishment of a state-of-the art Media House donated by JICA for in-house production of multi-media learning materials. By this time, even though multi-media materials were still being used sparingly, the OUSL had attained the $2^{\text {nd }}$ Generation.

More recently, in 2003, the Distance Education Modernization Project, (DEMP) supported by the Asian Development Bank and the Government of Sri Lanka embarked on an ambitious project on Online Learning at post-secondary education level. The overall goal of the DEMP was to increase socio-economic growth by developing a modern, high quality human resource base through online education, to raise quality and enhance capacity with the aim of setting up and managing a distance education network that provides assistance to develop curriculum content, training, mentoring, peer group support and interaction and maintenance of hardware and software. The project provided expertise, capacity building, technology transfer, equipment and software and recurrent costs (Gunawardena, 2008). Online learning developed under the DEMP would fall under the 4th Generation model of Flexible Learning as not only was the Internet being used for delivery of the programmes, for transmission of assignments and provision of feedback but it was also envisaged that social learning would take place, through chats, virtual canteens, discussion forums etc. Thus in two Online Learning programmes in Sri Lanka, Gunawardena and Karunanayake (2008) found that Cooperative Learning was the norm in communications.

Prominent among the Partner Institutions of the DEMP are universities which have developed online degree, diploma or certificate programmes, public institutions such as the Sri Lanka Institute of Development Administration, the Institute of Engineering Technology, professional associations and institutes such as the Sri Lankan Library Association, the Sri Lanka Institute of Marketing and the Institute of Certified Management Accountants as well as private educational institutions such as Informatics Institute of Technology and the Department of Vocational Studies, Ladies College.

These institutions offer diverse programmes in the fields of human rights, business administration, applied sciences, continuous 
professional development in medicine, information technology, teacher education, librarianship, disability studies and civil engineering. By the end of 2009, 40 programmes had been launched. It is significant that one of these programmes is being offered in Sinhala (Agrotechnology) and a second in Tamil (Business Management).

The interest shown by diverse educational institutions to develop online programmes as well as inquiries made by potential students with GCE (AL) qualifications is encouraging. Even though at present the availability of programmes in local languages restricts accessibility, it is certain that students who complete online programmes would undoubtedly have better chances of procuring employment, especially in view of their enhanced IT skills, improvements in English competency and skills of self-learning.

In 2009, the University of Colombo with assistance from the Republic Korea and Mobitel (a prominent telecommunication provider in Sri Lanka) launched an Executive Diploma in Marketing using m-learning. This programme marks progress from the earlier models in that as a result of flexibility in using mobile phones with laptop computers, students are facilitated to work anywhere, at anytime at their own pace. In terms of technology being used it is possible that $\mathrm{m}$-Learning as implemented in Sri Lanka would approximate the 4th Generation model, but the opportunities for student-student and student-teacher social interaction was much less than in the Online Learning used in the DEMP project.

In conclusion, it is pertinent for us to note that ODL as a mode of learning has the prime objective of facilitating learners who were mostly disadvantaged due to gender, age, lack of formal education, residence in remote locations or employed, who were denied tertiary, adult or life long education due to the various barriers that prevented them from continuing education. While for these groups of students technology is an effective strategy to overcome such barriers, the use of sophisticated technology which imposes additional barriers to pursuing education, should be considered with care. Any technology which does not facilitate those who are really disadvantaged and bequeaths advantages only to those who already have access to formal education should be weighed carefully for its costs and benefits. We have already looked at the pros and cons of choosing various models of ODL. In such a context, the multi-generational model proposed by Willems (2005) has much appeal. Her claim for proposing such a model is based on the argument that 'across the globe, multi-generational communities exist to support each other. Each generation draws on 
the strengths of the generation that exists before or after it: the wisdom of older generations, the exuberance and fresh thinking of the new generation". Willems suggests that models of distance learning can be considered as a family of co-existing 'generations' each still having valuable contributions to make to the study life of global distance learning. She argues that such a model may meet the needs of a broader range of distance learners in order to prevent a techno-elitist barrier to accessing and participating in distance education'. The multi-generational model would include access to print materials, audio-visual materials that do not require downloading from the university portal, and to tele-learning alternatives. It is imperative to ensure that technology-driven distance education proposed by the later generations of ODL does not alienate the already disadvantaged students from pursuing higher education.

\section{References}

Advisory Committee for Online Learning. The E-Learning E-Volution in Colleges and Universities: A Pan-Canadian Challenge. Ottawa: Industry Canada, Feb. 2001. Available at: www.cfs.fcee.ca (accessed 06/04/2010).

Bates, Tony (1995) Technology, Open Learning and Distance Education, Routledge (London and New York

Bates, A. W. (1996) The Impact of Technological Change on Open and Distance Learning. Keynote Presentation in Proceedings of the 2nd International Conference on Open Learning. 4-6 December 1996. Brisbane, Qld Australia.

Bates, Tony (2008) What is Distance education? http://www.tonybates.ca/2008/07/07/what-is-distance-education/ Accessed 02/04/2010

Berge, Z., and Collins, M. (1995) Computer-mediated communication and the online classroom in distance learning. Computer-Mediated Communication magazine, 2(4), http://www.ibbilio.org/cmc/mag/1995/apr/berge.html Accessed $\underline{02 / 04 / 2010}$

Charpentier, Monique, Christian Lafrance and Gilbert , International ELearning Strategies; Key findings relevant to the Canadian Context. Canadian Council on Learning 2006

Canadian Council on Learning (2009) State of E-Learning in Canada, Ottawa. www.ccl-cca.ca Accessed 29/03/2010 Charpentier, Monique, Christian Lafrance and Gilbert Paquette (COGIGRAPH/ 
TÉLUQ). International E-learning Strategies: Key Findings Relevant to the Canadian Context. Ottawa: Canadian Council on Learning, 2006. Available at: www.ccl-cca.ca (accessed 5/04/ 2010).

Department of Education, Training and Youth Affairs, Higher Education Division (Australia) (2001) Fifth generation Distance Education In higher education series, Report No.40, June www.dest.gov.au Accessed $28 / 03 / 2010$

Dondi, Claudio (1997) ODL Policy seminar: Executive Summary, SCIENTER, via val d'Aposa, 3-I-40123 BOLOGNA www.eurodl.org/materials/contrib./1997/odlpolic/dondi1.html Accessed 22/03/2010

Dory, Bertrand (2005) "Is there a return on investment for e-learning?" $e^{-}$ mentor 10 No. 3, http://www.ementor.edu.pl Accessed 22/03/2010

Else, R., and Hicks, R. (1998) Message received: Use of online technology for the delivery of vocational training in remote North West Australia: A feasibility study. South Hedland, WA: Hedland College of Social Research centre. Quoted in Willems (2005)

Ericsson, "Home: from e-learning to m-learning," http://learning.ericsson.net/mlearning2/project_one/index.html Accessed 08/04/2008

Feinstein, Leon, Vorhaus, John and Sabates, Ricardo Learning Through Life: Future Challenges, Foresight Mental Capital and Wellbeing Project Outputs Series (London, UK: The Government Office for Science, 2008). Available at: www.dius.gov.uk Accessed. 02/04/2008

Gunawardena, Chandra (2008) 'Online Learning for Extending Access and Facilitating Employability in Sri Lanka' Conference Abstracts 5th PanCommonwealth Forum on Open Learning, London, 2008

Gunawardena, Chandra and Karunanayake, Shironika (2008) 'Women's Participation in Online Learning in Sri Lanka: Study of Two Selected Courses- University of Moratuwa and Open University of Sri Lanka' Conference Abstracts $5^{\text {th }}$ Pan-Commonwealth Forum on Open Learning, London, 2008

Hall, Bethany and Cotterill1, Stewart (2004) E-Learning, IT Competencies, Computer Literacy and Student Attitudes to E-Learning Quoted in Canadian Council on Learning (2009) 
Open and Distance Learning Transformed: Possible Adaptations to Suit Special Contexts

Holmberg, B. (2001). Distance education in essence: an overview of theory and practice in the early twenty-first century. Oldenburg, Germany: Bibliotheks- und

Informationssytem der Universität Oldenburg.Internet World Stats (2009) Internet Users: Top 20 countries Miniwatts Marketing Group. http://www.internetworldstats.com/stats3.htm Accessed 05/04/2010

Keegan, P. (1986) The Foundations of Distance Education, Croom Helm, London

Legge, D. (1982) The Education of Adults in Britain, The Open University Press, Milton Keynes, England

Maxwell, L. (1995) Integrating Open Learning and Distance Education. Educational Technology November-December, 43-48.

Moore, M. G., \& Kearsley, G. (1996). Distance education: A systems view. Belmont, CA: Wadsworth Publishing Company.

Nipper, S. (1989) Third generation distance learning and computer conferencing. In R. Mason and A. Kaye (Eds.) Mindweaves: Communication, computers and distance education (pp.63-73) Oxford: Pergammon Press.

Organisation for Co-operation and Development (OECD), "E-learning intertiary education," Policy Brief (Dec. 2005). Available at: www.oecd.org/publications (accessed Oct. 13, 2008) Quoted in Canadian Council on Learning (2009)

Organisation for Co-operation and Development (OECD) "The future of the internet economy: a statistical profile" Presented at the OECD Ministerial meeting, Seoul, Korea, June 17-18, 2008 Quoted in Canadian Council on Learning (2009)

O’Malley, C., Vavoula, G., Glew, J.P. et al., Guidelines for Learning/Teaching/

Tutoring in a Mobile Environment, MOBIlearn deliverable D4.1 (Italy:MOBIlearn Consortium, 2003). Available at: www.leonardolets/net/common/download/MariaLuicaVinci.pdf Accessed $31 / 03 / 2010$

Rumble, G. (1989). On defining distance education. The American Journal of Distance Education, 3(2).

Rowntree, D. (1992) Exploring Open and Distance Learning. London: Kogan Page 
Rumble, G (1989), On defining distance education, The American Journal of Distance Education, 3 (2 ) 8-21

Taylor, J.C. (1999) Distance education: the fifth generation Proceedings of the $19^{\text {th }}$ ICDE World Conference on education, Vienna, Austria

Tella, S (2003) The Poor Relation of the Education System? Aspects of Distance Education and Open and Distance Learning,http://www.european-mediculture.org

Thrope (1988), Evaluating Open and Distance Learning, Harlow, Longman

University of Alberta, Vice-Provost (Information Technology), "E-learning in higher education," www.vpit.ualberta.ca/elearning/reports/elearning_report/2.php Accessed 5,04/2010

Ungerleider, C and Burns, T "Information and communication technologies in elementary and secondary education: a state of the art review," prepared for and presented at the 2002 Pan-Canadian Education Research Agenda Symposium, Montreal, April 30-May 2, 2002.Quoted in Canadian Council on Learning (2009)

Wagner, Nicole, Khaled Hassanein and Milena Head (2008) "Who is responsible for e-learning success in higher education? A stakeholder analysis" Educational Technology and Society 11 No.3, 26-36

Willems, Julie (2005) Spanning the 'generations': Reflections on twenty years of maintaining momentum http://www.ascillite.org.au/conferences/brisbane05/blogs/proceedings 183_Willems Accessed 28/03/2010

World Bank (2006) World Development Report 2007: Development and the Next Generation. Washington D.C.

Wylie, A. (1996) Open Learning: If it Looks Like DE, it's Okay. Proceedings of the 2nd International Conference on Open Learning. 4-6 December 1996. Brisbane, Qld Australia, 286-293. 